CASE REPORT

\title{
Perioperative Management in Patients with Factor XI Deficiency
}

\section{Antoine Legrand, Remi Bouquerel, Antoine Strzelecki, Benjamin Le Gaillard, Christophe Pelletier, Mireille Houadec and Edmundo Pereira de Souza Neto*}

\author{
Département d'Anesthésia, Centre Hospitalier de Montauban, France
}

*Corresponding author: Edmundo Pereira de Souza Neto, Département d'Anesthésia, Centre Hospitalier de Montauban, 100 rue Léon Cladel, 82013 Montauban, France

\section{Introduction}

Factor $\mathrm{XI}$ (FXI) is a plasma serine protease that contributes to thrombin generation primarily through proteolytic activation of factor IX. While FXI is necessary for normal coagulation in vitro systems individuals FXI deficiency have a variable bleeding risk that cannot be predicted from FXI antigen, FXI: Clotting activity, and activated partial thromboplastin time (APTT) [13]. The bleeding disorder in FXI-deficient patients has presented practical and conceptual challenges for clinicians [1-4].

In this article, we describe three cases of patients with FXI deficiency.

\section{Case Report}

\section{Case 1}

White French female patient, 56-years-old, $76 \mathrm{~kg}$, $170 \mathrm{~cm}$, was scheduled for a Left knee arthroplasty. Vital signs (blood pressure, temperature, oxygen saturation and Glasgow coma score) were normal. His ASA physical status was 2 and she had no treatment. Past medical history found a cervicobrachial neuralgia. Past surgical history consisted of bilateral hallux valgus, left knee arthroscopy, blepharoplasty and an ovarian ectopic pregnancy.

The patient had an history of abnormal clinical bleeding that needs a blood transfusion that were during the ovarian ectopic pregnancy surgery and for her two childbirth (vaginal delivery).

The complete blood count discovered only a low hemoglobin count $10.6 \mathrm{~g} / \mathrm{dl}$. Prothrombin time (PT) was $100 \%$ (normal range: $70 \%-100 \%$ ), activated partial thromboplastin time (APTT) with normal plasma [ratio 1:1] was 1.24 (Normal range: $0.80-1.20$ ). Her laboratory evaluation revealed an FXI level quantitated at $41 \%$.

A routine hematology consultation was obtained and a bleeding management strategy was established that was performing the surgical procedure with antifibrinolytic therapy with tranexamic acid $(1 \mathrm{~g}$ twice a day, for 10 days), avoid nonsteroidal antiinflammatory and use of Factor $\mathrm{XI}$ concentrates (Hemoleven ${ }^{\circledR}$, LFB) only if bleeding.

The surgery was done without any problem, bleeding was about $200 \mathrm{~mL}$ and no transfusion was needed.

The patient remained in the post-anaesthesia care unit for 80 minutes and then returned to her hospital room. She was discharged from the hospital the day after surgery. No adverse events have been reported.

\section{Case 2}

White French female patient, 33-years-old, $56 \mathrm{~kg}$, $156 \mathrm{~cm}$ was scheduled for a tubal ligation. Vital signs (blood pressure, temperature, oxygen saturation and Glasgow coma score) were normal. His ASA physical status was 2, her treatment was Levothyroxine $75 \mu \mathrm{g}$. Past medical history found a hypothyroidism. Past surgical history consisted of two deliveries without complication, bilateral inguinal hernia, appendectomy, tonsillectomy without problem. A wisdom teeth extraction done in 2016 presented a hemorrhagic complication and laboratory evaluation found a factor

Citation: Legrand A, Bouquerel R, Strzelecki A, Gaillard BL, Pelletier C, et al. (2019) Perioperative Management in Patients with Factor XI Deficiency. Int J Anesthetic Anesthesiol 6:086. doi. org/10.23937/2377-4630/1410086

Accepted: March 11, 2019: Published: March 13, 2019

Copyright: (C) 2019 Legrand A, et al. This is an open-access article distributed under the terms of the Creative Commons Attribution License, which permits unrestricted use, distribution, and reproduction in any medium, provided the original author and source are credited. 
$\mathrm{XI}$ deficiency with a rate of $36 \%$. There were no blood transfusions or pharmacologic agents given to promote hemostasis.

Her laboratory evaluation revealed an APTT at 1.27 (Normal range: $0.80-1.20$ ), PT at $87 \%$ (normal range: $70 \%-100 \%$ ) and a FXI level quantitated at $41 \%$.

After a hematology consultation, it was decided to perfuse $1 \mathrm{~g}$ preoperative of EXACYL, to avoid NSAIDs and low-molecular-weight heparin. Hemoleven ${ }^{\circledR}$ was made available in the operating room. However, as the surgery was done without bleeding, Hemoleven ${ }^{\circledR}$ or transfusion was not needed.

The patient remained in the post-anaesthesia care unit for 80 minutes and then returned to her hospital room. As no adverse events have been reported, she was discharged from the hospital the day after surgery.

\section{Case 3}

Black French female patient, 38-years-old, 90 kg, 165 $\mathrm{cm}$, was scheduled for an urgent caesarean because failed operative vaginal delivery. Vital signs (blood pressure, temperature, oxygen saturation and Glasgow coma score) were normal without foetal suffering. His ASA physical status classification was 2 . Her treatment was salbutamol if necessary and iron supplementation. Past medical history was a cured syphilis, allergic asthma, factor XI deficiency (discovered in previous pregnancy). She had no surgical history outside four normal deliveries.

In 2013, for the last delivery, FXI counts where $32 \%$, Hemoleven ${ }^{\circledR}$ made available, but not used because no hemorrhagic complication. Delivery was done without hemorrhagic or obstetric complications.

Her laboratory evaluation realized 3 weeks before caesarean revealed a factor XI with $47 \%$ activity, an APTT at 1.12 (Normal range: $0.80-1.20$ ) and a PT at $98 \%$ (normal range: $70 \%-100 \%$ ).

Hematology consultation stated that her blood deficit was a physiological deficit during pregnancy, which does not require any particular conduct.

Caesarean was done under general anesthesia, because $\mathrm{FXI}$ counts where at $24 \%$. An intravenous perfusion of $1 \mathrm{~g}$ of acid tranexamic was realized. The surgery was done without major bleeding and without the need to realize transfusion.

The patient remained in the post-anaesthesia care unit for 60 minutes before returned to her hospital room. She was discharged from the hospital the 4 days after surgery. No adverse events have been reported. Supplementation of an anemia by iron $\left(\right.$ Venofer $^{\circledR}$ ) (iron sucrose injection) was done.

\section{Discussion}

Factor XI (FXI) deficiency is an autosomal disorder that should occur in equal numbers in men and women and may be associated with bleeding $[1,3]$. Homozygotes and compound heterozygotes will have a factor level of less than $15 \%$ and the expected FXI level in heterozygotes is $25-70 \%[1,3]$.

While the incidence of severe FXI deficiency in the general population is estimated at only 1 in a million persons, the disorder is common in Ashkenazi (East European) Jews, in whom the carrier frequency for an abnormal FXI allele is about $8 \%$, and severe deficiency is present in one in every 450 persons [2-4].

Other terms for FXI deficiency include plasma thromboplastin antecedent deficiency, Rosenthal syndrome, and hemophilia $\mathrm{C}$. The International Committee for the Nomenclature of Blood Clotting Factors proposed FXI, to distinguish it from the factors missing in hemophilia A (Factor VIII), hemophilia B (Factor IX), and Hageman trait (Factor XII) [1-3].

Patients with FXI deficiency do not need treatment or prophylaxis for routine functions or activities [1-3]. The treatment of FXI deficiency is not always straightforward because the bleeding tendency is unpredictable and does not correlate with residual enzyme activity [1-3]. The size of the surgery, the risk of bleeding and the factor level of the patient are important for the decision if the FXI should be replace or not. However, it is generally accepted that bleeding might be more important in severe deficiency of FXI (FXI level $<15$ to $20 \%$ of normal) [1-3,5].

The association between the amount of FXI in plasma as determined by the activated partial thromboplastin time (aPTT) and bleeding propensity is weak, aPTT may not be correlate with hemorrhagic tendency [1-3].

In general, treatments for FXI deficiency include FXI concentrate, fresh frozen plasma and the use of antifibrinolytic drugs or desmopressin. Desmopressin (0.3$0.4 \mu \mathrm{g} / \mathrm{kg}$ given intravenously or subcutaneously) has also been shown to increase the activity of the factor $\mathrm{XI}[2,6,7]$. In cases with minor bleeding, tranexamic acid ( $15 \mathrm{mg} / \mathrm{kg}$ or $1 \mathrm{~g}, 3$ times daily) can be considered $[2,5]$. In cases with severe bleeding, an initial dose of FXI concentrates (10-15 IU/kg) or fresh frozen plasma $(20 \mathrm{~mL} / \mathrm{kg}$ ) can be given, with or without the addition of tranexamic acid, depending on the degree of bleeding. FXI concentrate should not be given along with tranexamic acid [2,7]. Combination of plasma and tranexamic acid has been suggested instead of FXI concentrate, but combined use of plasma and tranexamic acid remains a controversial practice $[2,5]$. Several reported cases use recombinant factor VIla but it has been associated with thrombosis [5].

In parturient, some authors stated that FXI level should be maintained $>35 \%$ during labor and for 3-4 days after vaginal delivery and 6-7 days after cesarean section [1-3]. Bolton-Maggs, et al. [8] proposed that if 
patients have 4 of the following symptoms, they can be classified as "bleeders": 1 - Bruising tendency; 2 Mucous membrane bleeding, epistaxis, gastrointestinal bleeding, and hematuria; 3 - Heavy menstrual bleeding requiring treatment; 4 - Any (excessive) bleeding postsurgery; 5 - Bleeding post dental extractions; 6 Bleeding related to childbirth [8].

If FXI level during the third trimester is $<20 \%$, FXI concentrate or plasma should be considered in symptomatic patients or patients with no prior hemostatic challenge. Prophylaxis using tranexamic acid should be considered $[2,3,5]$.

If FXI level during the third trimester is between $20 \%$ and $70 \%$ and patient has a history of bleeding, or no prior hemostatic challenges, tranexamic acid can be considered $[2,3,5]$.

In case where $\mathrm{FXI}$ activity during the third trimester is between $20 \%$ and $70 \%$ and patient had no prior bleeding despite hemostatic challenges, treatment should be considered only if abnormal bleeding occurs $[2,3,5]$.

Actually, evidence on the choice of anesthesia technique in parturient with FXI deficiency is based only on case series and reports [2,4]. It is difficult to draw a recommendation in favor of a particular technique. However, the consequence of epidural hematoma with irreversible paraplegia may make it an unacceptable risk to be taken on the basis of current limited evidence $[2,4]$.

The practice of prophylactic plasma transfusion to perform a neuraxial intervention is not advised because it may provide more risk than presumed benefit $[2,5]$.

We had three patients with low FXI, but no major deficiency (under 15\%) and we did not observe any hemorrhagic complication. A protocol was established in accordance with the specialized opinion and the actual knowledge of FXI deficiency and kind of surgery. Expectant treatment of a pregnant woman is controversial if a cesarean delivery is not planned. In our case, because it was not deep deficiency of FXI and no major risk of bleeding surgery, no prophylactic supplementation of FXI was judged necessary. Only general measures where established with perfusion of acid tranexamic, restriction use of medication with hemorrhagic potential and FXI concentrates available in necessary. This type of support can be used in case of other moderate FXI deficiency, and with there is no major risk of bleeding surgery. However, this does not preclude contacting a reference hematologic center.

\section{Conclusions}

Factor XI deficiency is an autosomal disorder and replacements should be done based in the kind of surgery, the risk of bleeding and the factor XI level. Treatments for FXI deficiency include FXI concentrate, fresh frozen plasma and the use of tranexamic acid or desmopressin. A multidisciplinary organization in patient management should be done to reduce the complications.

\section{Informed Consent}

Written informed consent was obtained from patients who participated in this case report.

\section{Peer-Review}

Externally peer-reviewed.

\section{Conflict of Interest}

No conflict of interest was declared by the authors.

\section{Financial Disclosure}

The authors declared that this study has received no financial support.

\section{References}

1. Duga S, Salomon O (2013) Congenital factor XI deficiency: An update. Sem Thromb Hemost 39: 621-631.

2. Shander A, Friedman T, Palleschi G, Shore-Lesserson L (2018) The evolving dilemma of factor XI in pregnancy: Suggestions for management. Anesth Analg 126: 20322037.

3. Wheeler AP, Gailani D (2016) Why factor XI deficiency is a clinical concern. Expert Rev Hematol 9: 629-637.

4. Verghese L, Tingi E, Thachil J, Hay C, Byrd L (2017) Management of parturients with Factor XI deficiency$10 y e a r$ case series and review of literature. Eur $\mathrm{J}$ Obstet Gynecol Reprod Biol 215: 85-92.

5. Mumford AD, Ackroyd S, Alikhan R, Bowles L, Chowdary P, et al. (2014) Guideline for the diagnosis and management of the rare coagulation disorders: A United Kingdom haemophilia centre doctors' organization guideline on behalf of the british committee for standards in haematology. $\mathrm{Br} \mathrm{J}$ Haematol 167: 304-326.

6. Franchini $M$, Manzato $F$, Salvagno GL, Montagnana M, Lippi G (2009) The use of desmopressin in congenital factor XI deficiency: A systematic review. Ann Hematol 88: 931-935.

7. Obaji S, Alikhan R, Rayment R, Carter P, Macartney N, et al. (2016) Unclassified bleeding disorders: outcome of haemostatic challenges following tranexamic acid and/or desmopressin. Haemophilia 22: 285-291.

8. Bolton-Maggs PH, Patterson DA, Wensley RT, Tuddenham EG (1995) Definition of the bleeding tendency in factor XIdeficient kindreds-a clinical and laboratory study. Thromb Haemost 73: 194-202. 